\title{
Are there monetary clusters in the Eurozone? The impact of ECB policy
}

\author{
Helena Dominguez-Torres*, Luis Ángel Hierro \\ Departamento de Economía e Historia Económica, Universidad de Sevilla, AVDA. Ramón y Cajal, 1, 41018 Sevilla, \\ SpainUniversity of Seville, Departamento de Economía e Historia Económica, Spain
}

Received 6 January 2019; received in revised form 1 September 2019; accepted 22 November 2019

Available online 19 December 2019

\begin{abstract}
This paper analyses what effects the monetary policy of the European Central Bank have on the economic activity of Eurozone countries. We identify groups of countries which exhibit different economic responses to monetary policy and the factors driving such spatial differences. We distinguish three periods, spanning from 2001 to 2017 and examine conventional as well as unconventional monetary policies in different economic backgrounds of expansion and crisis. We find problems of spatially asymmetric transmission of monetary policy in the period 2008M10-2014M12 and note that different spatial responses might operate in favour of monetary policy or be indifferent to this policy.

(C) 2019 The Society for Policy Modeling. Published by Elsevier Inc. All rights reserved.
\end{abstract}

JEL classifications: E52; E58; F45; C38

Keywords: European Central Bank; Monetary policy; Spatial effects; Cluster analysis

\section{Introduction}

Monetary policy is designed and implemented in a spatial-blind manner, as if the politicaleconomic space on which it exerts its impacts were uniform. However, it is highly unlikely that any policy is spatially-blind (see Hewings, 2014) since political-economic space is not uniform

\footnotetext{
* Corresponding author.

E-mail addresses: dothelena@gmail.com, heldomtor@alum.us.es (H. Dominguez-Torres), lhierro@us.e (L.Á. Hierro).
} 
(see Mann, 2010). In fact, what the literature suggests regarding this issue is that monetary policy gives rise to different effects across geographical space because of the differing spatial intensity of monetary transmission mechanisms. Indeed, the differing degree of spatial operativity in the case of the interest rate channel has been found to depend on the spatial distribution of economic sectors (see Carlino \& DeFina, 1998, 1999; Owyang and Wall, 2009; Ridhwan, de Groot, Rietveld, \& Nijkamp, 2014; Rocha, Silva, \& Gomes, 2011; Vespignani, 2015); in the case of the exchange rate channel on the spatial pattern of trade openness (see Vespignani, 2015), and in the case of the credit channel on the financial, banking and firm spatial structure (see Carlino \& DeFina, 1998, 1999; Guo and Tajul, 2017; Owyang and Wall, 2009). Such heterogeneity in the spatial effects stemming from monetary policy has been studied extensively in its empirical dimension. A very recent review of this literature is provided by Dominguez-Torres and Hierro (2019). As regards the euro area, most recent studies on the cross-country effects on economic activity resulting from European Central Bank (ECB) monetary policy, such as those by Cavallo and Ribba (2015), Boeckx, Dossche, and Peersman (2017) or Burriel and Galesi (2018), do indeed reveal heterogeneity in the cross-country responses analysed.

With the diverging spatial impacts that result from implementing ECB monetary policy having repeatedly been demonstrated, one question that follows is how these effects are spatially distributed and if countries are clustering around different levels of responsiveness to monetary policy. In other words, interest now lies in identifying and quantifying similarities and divergences in the impacts exerted by ECB monetary policy across countries. This is analysed by determining whether there are, or have been, monetary clusters in the Eurozone. We define a monetary cluster as a set of countries whose main economic variables react in a similar fashion to a specific ECB monetary policy. Furthermore, interest has also shifted towards identifying which factors seem to influence the spatial distribution of such effects, that is, which factors give rise to monetary clustering and explain similarities and divergences in the impacts exerted by ECB monetary policy across countries. In addition to other issues detailed later on, the importance of determining whether monetary clusters exist in the Eurozone is related to the possible impact of such clusters on the monetary policy implemented by the ECB. Such an issue is of major political and economic significance within the current economic and political climate of the Eurozone.

The wide-ranging debate surrounding ECB policy is well known, with economists from both sides of the Atlantic having participated (Brunnermeier, James, \& Landau, 2016; De Grauwe, 2011; Krugman, 2012; Stiglitz, 2016, to name but a few), and with the debate having even transcended to the judicial field. Since 2010, after the implementation of the first strictly unconventional measures, a major controversy broke out in Germany. In April 2011, the governor of the Bundesbank, Axel Weber, who was destined to succeed Trichet in the ECB, resigned for personal reasons, although it was speculated that he strongly disagreed with Merkel over the purchase of sovereign debt through the so-called Securities Market Program (SMP). In September 2011, the German board member Jürgen Stark, Chief Economist of the ECB, resigned due to his opposition to the public debt purchase policy, and by late August 2012, just after Draghi's announcement of selective public debt purchase, known as Outright Monetary Transactions (OMT), the President of the Bundesbank Jens Weidmann reportedly threatened to resign if Germany supported such measures. Opposition to these measures in Germany was such that an activist group of economists, citizens and German MPs, who had already lodged an appeal against the bailouts, filed a judicial appeal against the OMT, which proved to be the most effective and apposite measure adopted by the ECB throughout the crisis since, merely by announcing it and without it even having to be applied, it put an end to the sovereign debt crisis. The appeal was finally rejected by the German 
Federal Constitutional Court in 2016 after consultation with the European Court of Justice (see Sáinz de Vicuña Barroso, 2016).

Specifically, an analysis of monetary clusters might shed light on whether the controversy generated within the euro area regarding the nature of the measures implemented by the ECB since the break out of the economic and financial crisis is related to the differentiated spatial effects arising from monetary policy or whether, by contrast, it is related to ideological issues.

From a strictly scientific standpoint, identifying monetary clusters in the Eurozone and using them as an analysis tool helps us to gain deeper insights into a number of issues, beyond studying whether the monetary policy implemented by the ECB exerts a differential economic impact across countries. These issues include (1) the patterns of the spatial distribution of these effects, that is, the analysis of whether there are similarities in the effects identified across geographical space which result in the creation of groups of countries that display similar economic reactions to monetary policy, as well as the quantification of such similarities; (2) the factors which seem to shape the spatial distribution of monetary policy effects on economic activity and which explain crosscountry similarities and divergences, and, finally, (3) whether the results to emerge might justify the discrepancies expressed by some countries, mainly Germany, in relation to ECB monetary policy or, in other words, whether the spatiality of monetary policy justifies different and even contrasting interests regarding the implementation of monetary policy within the Eurozone.

In the present paper, we aim to provide answers to the previous issues by using time-series techniques together with machine learning methods. Specifically, we apply autoregressive vector models, which allow us to overcome problems of simultaneity and endogeneity among outcome and policy variables, and cluster analysis methods. We use data from 2001 to 2017, dividing the analysis into three periods corresponding to three different monetary and economic contexts: a conventional monetary policy period (2001-2008); a non-conventional pre-quantitative easing monetary policy period (2008-2014); and a quantitative easing period (2015-2017). Such a threefold division allows us to go beyond existing studies and to examine whether the spatial dynamics of monetary policy and its drivers are time-varying or, by contrast, whether are static. Put differently, it allows us to analyse whether the distribution of the effects of monetary policy across countries exhibits a changing nature contingent on the monetary-economic context or whether it remains the same irrespective of such a context.

Moreover, adopting a cluster approach makes a further twofold contribution to the literature. First, it allows spatial patterns of the effects of monetary policy beyond the traditional crosscountry dimension to be identified and quantified. Second, it also allows us to determine the nature of the factors driving the spatial distribution of these effects by identifying whether such factors display within-cluster commonality or whether, by contrast, they constitute country-specific singularities which, although specific to each country, give rise to similar impacts that ultimately translate into the conformation of clusters. This is done by analysing whether the clusters identified are profiled by explanatory variables through an analysis of variance (ANOVA).

The analysis is structured as follows: in section two, we describe the monetary policy implemented by the ECB since the Euro was put into circulation. The empirical analysis is then divided into three parts: (Section 3) definition and estimation of an autoregressive model in order to determine the cross-country impacts of monetary policy on output and prices; (Section 4) a clustering analysis of the spatial effects identified above, and (Section 5) an analysis on the factors explaining similarities and divergences across geographical space using analysis of variance (ANOVA). The final section sums up the conclusions to emerge from the previous analyses and outlines the consequences of such analyses for European monetary policy. 


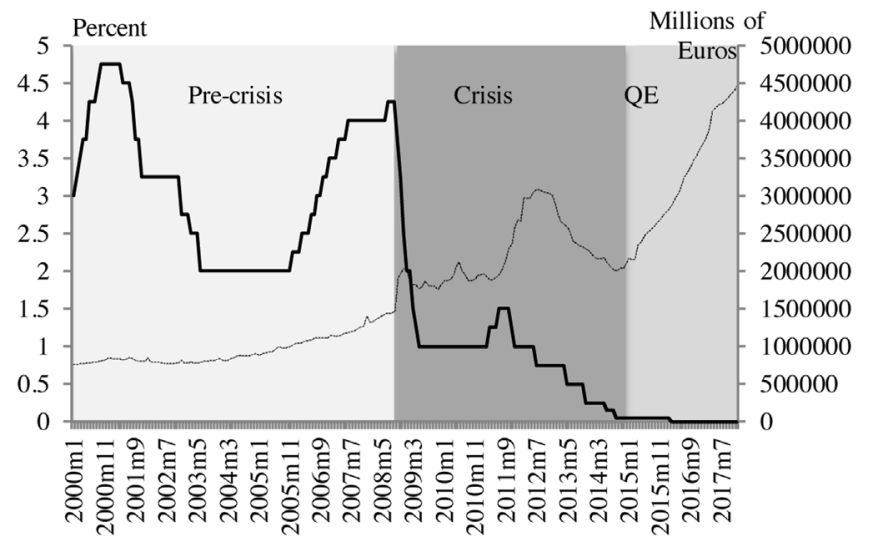

Fig. 1. Eurosystem balance sheet and Main Refinancing Operations Rate. Source: Authors' compilation based on data of ECB statistical data warehouse.

\section{European Central Bank monetary policy. Different times different policies}

Since its creation, the ECB has established interest rate control as the ordinary operating mechanism of its monetary policy, specifically by operating over the minimum bid rate of regular open market operations. This interest rate was thus mainly steered by establishing the amount of liquidity provided in the Main Refinancing Operations (MRO). This mechanism was applied until October 2008. However, by mid-2007 this mechanism was already proving to be insufficient due to bank liquidity problems associated with uncertainty caused by structured financial assets. The bankruptcy of a BNP Paribas fund in August 2007 dried up the interbank market and forced the central bank to take exceptional coordinated liquidity measures. However, these measures did not alter the interest rate operating mechanism used by the ECB. As can be seen in Fig. 1, liquidity restrictions did not involve any changes in the MRO, which remained at $4 \%$. In other words, conventional European monetary policy was applied during this period.

As of October 2008, given the collapse of the international financial system, the picture changed completely. The ECB drastically reduced the interest rate, with the MRO dropping from $4.25 \%$ to $1 \%$ between October 2008 and May 2009. In Fig. 1 we also see how besides the MRO experiencing an important drop around October 2008, the ECB balance sheet increased by around 500 billion Euros. This is due to the fact that in general, central banks adopted measures that would have been inconceivable just a few months earlier and which implied important increases in their balance sheets. Indeed, some of these measures had never been applied before and pursued specific and even multiple objectives which differed from the traditional ones sought by monetary policy. In Europe, the problem was amplified vis-à-vis other monetary zones because of the sovereign debt crisis and the constitutional restriction in place in the ECB with regard to financing states and the non-bailout clause (articles 123 and 125 of the Treaty on the Functioning of the European Union). By applying the Wald test, we confirm a structural break on October 2008, which prompts us to consider that we should analyse at least two different periods: one prior to the crisis, spanning from January-2001 to October-2008 (henceforth "period 1") and another spanning the period after the crisis.

Within the period from October 2008 to December 2017, the first part (October 2008-December 2014) includes the international financial crisis and the European sovereign debt crisis, where 
myriad monetary policy instruments were deployed. The variables display peaks, and the purpose of monetary policy and its instruments is not evident. Of all the measures, actions on longterm monetary loans, that is, long-term refinancing operations (LTROs), were the ones that most increased the size of the balance sheet after October 2008. Fig. 1 clearly shows the peak in the balance sheet exceeding 3000 billion euros resulting from the three-year LTROs applied between November 2011 and February 2012. The effects of such LTROs were felt until 2014 when the last amortizations took place. Strictly speaking, these measures did not constitute quantitative easing. Indeed, Borrallo Egea and Hierro (2019) highlight the transitory nature of the increase in the balance sheet of the ECB during this period. Consequently, this period of acute crisis and uncertainty or monetary policy transition will be termed "period 2" and will be examined separately.

The last period, called "period 3" (January 2015-December 2017), is characterised by a zero lower bound context, while monetary policy was implemented by means of systemic open market operations known as the asset purchase programme (APP), within which the main programme was the public sector purchase programme (PSPP). Monetary policy is therefore clearly directed towards quantitative easing. Period 3 commences in January 2015, since this is when the quantitative expansion first applied in March was announced, thus capturing the announcement effect.

In sum, the ECB has undergone a radical transition linked to the changes that have taken place in the economic situation and which have meant a shift from the initial operational instrument of period 1, that is, the interest rate, to the operational instrument of controlling the monetary supply in period 3, while what might be termed "temporary quantitative easing" prevailed in an intermediate transitional period (period 2).

The direct consequence of these changes in policy and in the economic situation for our study is that we analyse the spatiality of two types of monetary policy: for period 1, and in line with the literature exploring conventional measures, we examine the effects of contractive monetary policy implemented by steering the interest rate, while for periods 2 and 3, in accordance with the main measures adopted, whether transitory or permanent, and which are reflected in the growth of the Eurosystem balance sheet, we analyse an expansive monetary policy of an increased amount of money, irrespective of whether such a policy seeks to reactivate monetary policy transmission (period 2) or expand demand and supply (period 3).

\section{Estimating the cross-country effects of European Central Bank monetary policy}

The first step in our study involves determining the cross-country effects on economic activity stemming from the monetary policies for each period considered.

\subsection{The model: benchmark specification}

Following recent studies in this field, such as Cavallo and Ribba $(2015,2018)$ and Boeckx et al. (2017), we use a near-VAR model to estimate the cross-country effects of monetary policy. The model estimated for each country is as follows:

$$
\left[\begin{array}{l}
y_{1, t} \\
y_{2, t}
\end{array}\right]=\left[\begin{array}{l}
v_{1} \\
v_{2}
\end{array}\right]+\sum_{l=1}^{p}\left[\begin{array}{ll}
A_{11}(l) & A_{12}(l) \\
A_{21}(l) & A_{22}(l)
\end{array}\right]\left[\begin{array}{l}
y_{1, t-l} \\
y_{2, t-l}
\end{array}\right]+\left[\begin{array}{l}
\mathcal{E}_{1, t} \\
\mathcal{E}_{2, t}
\end{array}\right]
$$


where $y_{1, t}$ is the aggregate variables vector for the Eurozone, and $y_{2, t}$ is the country-specific vector. $\mathcal{E}_{t}=\left(\mathcal{E}_{1, t} \mathcal{E}_{2, t}\right)$ is a disturbances vector, while $v=\left(v_{1} v_{2}\right)$ is the intercept vector. The number of lags is indicated by $p$. Through restriction $A_{12}(l)=0$ for each $l=1, \ldots, p$, we impose no feedback from the country-specific block to the aggregate variables block. Thus, even if we estimate a VAR model for each country, the estimated dynamics for the euro area remain the same, as does the estimated shock for each country (see Cavallo and Ribba, 2018). This allows us to infer cross-country comparisons. Moreover, through this specification we reduce the number of parameters to be estimated.

The aggregate block includes five variables: gross domestic product (GDP); the harmonised index of consumer prices (HICP); an indicator of conventional monetary policy proxied by the main refinancing operation rate (MRO); a measure of financial stress and economic risk at the euro area level proxied by the composite indicator of systemic stress (CISS) developed by Holló, Kremer, and Lo Duca (2012); and a proxy of non-conventional monetary measures, proxied by the Eurosystem balance sheet since most of the measures adopted by the ECB from 2008 onwards have an impact thereon (see Gambacorta, Hofmann, \& Peersman, 2014; Kremer, 2016; Boeckx et al., 2017; Burriel \& Galesi, 2018). The country-specific block $y_{2, t}$ includes the two variables analysed for each country: country GDP and prices.

We use the variables in log levels (with the exception of MRO and CISS). Implicit cointegration relationships are therefore allowed to exist.

Variable frequency is monthly. We therefore interpolate real GDP (following Boeckx et al., 2017) employing the Chow-Lin method (1971) using monthly industrial production as the reference series.

Given the scant number of observations and the limitation this imposes on the degrees of freedom, we use a parsimonious model. For the longer periods (1 and 2), two lags are thus selected, whereas for period 3, given its particular brevity, one lag is employed.

We employ a Cholesky decomposition as the benchmark specification. The underlying assumption is that the ECB (at least partially) bases its decisions on analysing the current state of the economy. The ordering is therefore prices, GDP, CISS and the monetary policy block. Within this monetary block, the relation between conventional and non-conventional monetary policy is modelled in such a way that the MRO is placed before the balance sheet (see Boeckx et al., 2017; Gambacorta et al., 2014; Kremer, 2016). The underlying rationale of such an assumption is: if the balance sheet is allowed to contemporaneously react to MRO shocks the potential endogenous reaction of bank liquidity demand to changes in the interest rate is captured, whereas by restricting the effect of a balance sheet shock on the MRO we are assuming that such a rate is set independent of bank liquidity needs (Kremer, 2016).

\subsection{Results}

For our calculations, we use the maximum accumulated impact of monetary policy, that is, the maximum total welfare gain/loss of output and prices derived from a monetary shock. Onestandard deviation shocks are calculated, which in period 1 implies a temporary increase in the MRO of 13.4 basis points, while in periods 2 and 3 it implies a temporary increase of $2.3 \%$ and $1.4 \%$, respectively, in the Eurosystem balance sheet. 
Table 1

Maximum cumulative impacts resulting from the implemented monetary policy for each country and period under analysis.

\begin{tabular}{|c|c|c|c|c|c|c|}
\hline & GDP-P1 & Prices-P1 & GDP-P2 & Prices-P2 & GDP-P3 & Prices-P3 \\
\hline Germany & -6.99 & -6.10 & 0.36 & 0.00 & 2.96 & 1.29 \\
\hline Austria & -10.84 & -6.00 & 0.19 & 0.13 & 2.91 & 1.90 \\
\hline Belgium & -10.54 & -5.81 & 0.21 & 0.76 & 2.35 & 2.98 \\
\hline Spain & -13.82 & -10.16 & -3.47 & 1.59 & 4.33 & 0.00 \\
\hline Finland & -12.82 & 0.00 & 0.91 & 0.00 & 3.26 & 0.75 \\
\hline France & -8.00 & -5.76 & 0.00 & 0.42 & 2.00 & 0.80 \\
\hline Greece & -13.24 & -9.08 & -4.85 & 2.07 & 0.00 & 0.80 \\
\hline Netherlands & -9.00 & -3.80 & -1.28 & 0.63 & 3.91 & 0.00 \\
\hline Ireland & -9.27 & -3.80 & -4.84 & 0.59 & 9.64 & -0.17 \\
\hline Italy & -6.90 & -5.81 & -1.41 & 1.06 & 1.84 & 0.00 \\
\hline Luxembourg & -18.20 & -9.87 & -2.33 & 0.56 & 3.69 & -0.19 \\
\hline Portugal & -7.01 & -7.78 & -1.47 & 0.96 & 2.94 & 1.52 \\
\hline Mean & -10.56 & -6.16 & -1.49 & 0.73 & 3.31 & 0.74 \\
\hline Std. Dev. & 3.45 & 2.87 & 2 & 0.62 & 2.29 & 1 \\
\hline
\end{tabular}

Source: authors' calculations based on data collected in Appendix A.

Note: results in percent.

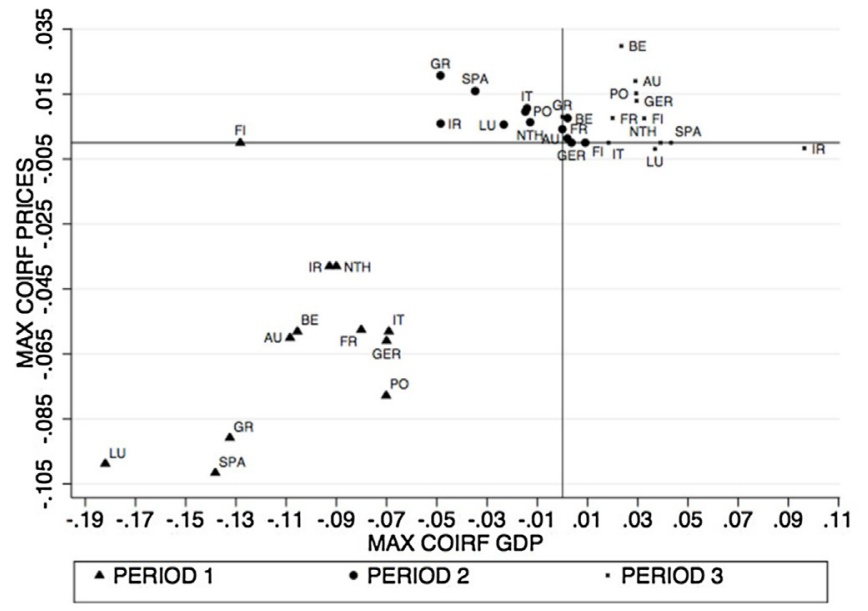

Fig. 2. Maximum cumulative impacts resulting from the implemented monetary policy for each country and period under analysis.

Note: $\mathrm{AU}=$ Austria; $\mathrm{Be}=$ Belgium; FI = Finland; FR = France; GER = Germany; GR = Greece; IR = Ireland; IT =Italy; $\mathrm{Lu}=$ Luxembourg; $\mathrm{NTH}=$ Netherlands $; \mathrm{PO}=$ Portugal; SPA = Spain. Results in decimal form.

Source: authors' calculations based on data collected in Appendix A.

Table 1 displays the maximum cumulative impacts over the forty-eight months following the monetary shock (thirty-six in the case of period 3) while in Fig. 2 the effects are graphically represented. ${ }^{1}$

\footnotetext{
${ }^{1}$ For countries whose impulse response functions are not statistically different from zero, the impact is deemed to be null. Confidence bands are calculated at $84 \%$ by means of the Gibbs sampling procedure with 4000 replications. When considering the response of prices in period 3, there exist three countries (France, Germany and Greece) which are borderline statistically significant and could be interpreted either as significant or not significant according to the tendency
} 
In quantitative terms, the spatial patterns exhibit different degrees of unevenness across periods. The most heterogeneous pattern is seen for period 1, whereas period 3 gives rise to the most uniform spatial pattern in terms of GDP excluding the outlier of Ireland. In terms of prices the most uniform pattern is seen for period 2 tough. Standard deviations for each period are: 3.45, 2 and 1.19 (2.29 if Ireland is taken into account) in the case of GDP, and 2.87, 0.62 and 1 (0.98 in scenario (2)) in the case of prices.

In order to validate the previously obtained conclusions, we performed robustness checks across several dimensions by (1) changing the order of the variables, and (2) by specifying a simultaneous interaction between monetary policy and the indicator of financial and economic risk by estimating a structural VAR. The maximum cumulative cross-country impacts obtained using the alternative identifications display a high degree of correlation with the impacts stemming from benchmark identification [supplementary material available upon request from the authors]. It can therefore be concluded that the spatial patterns identified are robust to the alternative identifications of the shock. ${ }^{2}$

\section{Similarities and divergences across countries: a clustering analysis}

Results reveal the dispersion in the effects of monetary policy and therefore point to the existence of a spatial difference. Determining the distribution of such effects across countries and whether these countries cluster around different levels of economic reaction to monetary policy is our next goal. This is performed by identifying monetary clusters, which are herein understood as groups of countries exhibiting a high degree of intra-group similarity or cohesion with regard to the effects stemming from ECB monetary policy and a high degree of inter-group dissimilarity or divergence among the results across groups. By identifying such clusters, we are able to assess and quantify similarities and divergences across countries's responses to monetary policy.

\subsection{Methodology}

In order to determine the existence of a cluster, we apply Ward's agglomerative hierarchical clustering method (1963) using the Euclidean distance. The within-cluster variance is termed as "error sum of squares" (ESS). For a given cluster X, ESS is given by

$$
\operatorname{ESS}(X)=\sum_{x_{n} \in X}\left\|x_{n}-\bar{x}\right\|^{2}
$$

where $\bar{x}$ is the average of the elements of cluster X. The Ward's linkage function can be expressed as

$$
D_{w}(X, Y)=\operatorname{ESS}(X \bigcup Y)-[\operatorname{ESS}(X)+\operatorname{ESS}(Y)]
$$

We also performed a robustness analysis by applying Complete linkage clustering [supplementary material available upon request from the authors].

\footnotetext{
shown by their confidence intervals. We will consider the two cases: scenario (1) corresponds to the responses being statistically significant whereas scenario (2) corresponds to the responses not being considered statistically significant. We only display the results for scenario (1), whereas we briefly indicate if scenario (2) gives rise to any changes with respect to scenario (1) in the analyses that follow.

2 The cumulative impulse response functions from the benchmark estimation and the robustness alternative specifications are available from the authors upon request.
} 
Results are presented in the form of a dendrogram. We then determine the optimal number of clusters. In order to ensure a robust analysis, we determine the number of clusters by means of joint reading, as far as possible, of a local and a global criterion. As regards the global criterion, we opt for the so-called elbow method (Thorndike, 1953). In the case of the local criterion, we employ the ratio criterion $\mathrm{Je}(2) / \mathrm{Je}(1)$ and its associated pseudo T-square index (Duda, Hart, \& Stork, 2001). It is standard practice in the literature to choose a number of clusters that corresponds both to a high value of $\mathrm{Je}(2) / \mathrm{Je}(1)$ and to a low value of the Duda-Hart pseudo T-square that has much larger pseudo T-squared values next to it, without these values having to necessarily correspond to the maximum or minimum values (Mooi, Sarstedt, \& Mooi-Reci, 2018). When reading the two criteria fails to yield a conclusive result, we resort to the silhouette method (Rousseeuw, 1987) as a deciding criterion. Since the clusters identified must differ substantially with one another (Mooi $\&$ Sarstedt, 2014), we compare the means of the clustering variables through ANOVA analysis (Fisher, 1925). Finally, once variance analysis has been performed, the post-hoc Tukey test is applied to identify pairwise differences.

\subsection{Results}

The obtained results are displayed in the respective dendrograms. Therein, GDP clusters refer to clusters identified on the basis of GDP responses (namely, maximum cumulative GDP impulse responses), and price clusters refer to clusters identified on the basis of price responses (maximum cumulative price impulse responses) (Fig. 3).

We next carried out the analysis on the optimal number of clusters. Table 2 summarizes the results obtained from this analysis (results of the Elbow method and the Duda/Hart statistics are available in the supplementary material upon request from the authors).

Finally, we proceeded to perform ANOVA tests on the previous results. In period 1, the ANOVA test confirmed the existence of two clusters in terms of GDP (results of the ANOVA and Post-hoc tests available in the supplementary material upon request from the authors). Table 3 displays cluster's composition. These clusters are characterised because they react in a similar fashion to a contractive shock, although cluster 1 is more compact, while cluster 2 (Spain, Luxembourg, Greece, and Finland) exhibits a considerably more reactive pattern. The difference between cluster 1 and cluster 2 GDP means is 5.95 percent points. In terms of price responses, the Tukey posthoc test confirms that the four clusters identified differ statistically with one another. With the exception of Finland, all the clusters experience a decrease in prices, which is consistent with a contractive monetary shock, although there are significant quantitative differences among the responses. The cluster including Spain, Luxembourg, and Greece again emerges as the most reactive.

In terms of the impact on GDP in period 2, the Tukey test confirms statistically significant differences among the three clusters identified. These differences are both quantitative and qualitative. In the case of cluster 1 (Germany, Austria, Belgium, France, and Finland) the monetary policy of transitory quantitative easing reactivates (albeit very modestly) economic activity, whereas in the other two clusters it does not. The degree of "failure" does, however, differ among these latter two clusters. As for the impact on prices, the ANOVA test confirms the existence of two clusters. Monetary policy gives rise to a slight increase in prices for both clusters, with the Spain and Greece cluster exhibiting the more reactive pattern.

As regards the impact on GDP in period 3, the ANOVA test confirms the existence of an outlier (Ireland). It can therefore be concluded that the monetary policy of quantitative easing implemented by the ECB as of March 2015 (even if different degrees of sensitivity to monetary 

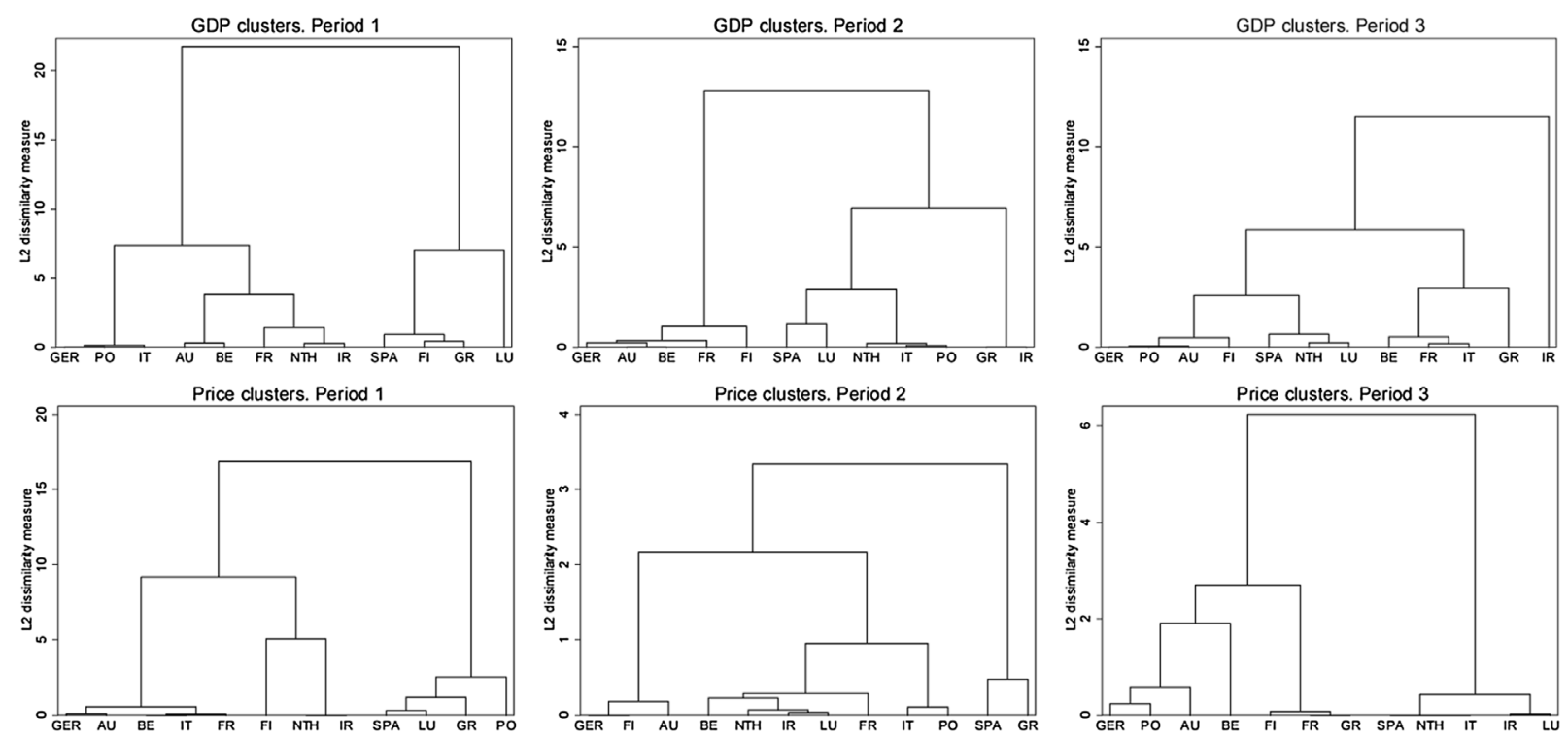

Source: authors' calculations based on data collected in Appendix A.

Fig. 3. Dendrograms. 
Table 2

Optimal number of clusters indicated by the selection criteria.

\begin{tabular}{lllllll}
\hline & \multicolumn{3}{l}{ Number of GDP clusters } & \multicolumn{3}{l}{ Number of price clusters } \\
\hline Period & 1 & 2 & 3 & 1 & 2 & 3 \\
Elbow method & 2 & $2-3$ & 2 & $2-4$ & 2 or 3 & 2 \\
Duda/Hart & 2 & $2-3$ & 2 & 2 or 4 & - & 2 \\
Silhouette & - & 4 & - & 4 & 2 & - \\
Number of clusters selected & 2 & $3^{\mathrm{a}}$ & 2 & 4 & 2 & 2 \\
\hline
\end{tabular}

Source: authors' calculations based on data collected in Appendix A.

a Since the silhouette method indicates an optimal number of clusters which is closer to three than two clusters, we deem that there exist three clusters.

Table 3

Composition of the identified clusters.

\begin{tabular}{|c|c|c|c|}
\hline & Cluster composition & Mean & Standard deviation \\
\hline \multicolumn{4}{|c|}{ Period 1} \\
\hline \multicolumn{4}{|c|}{ GDP clusters } \\
\hline 1 & GER, PO, IT, FR, AU,BE, NTH, IR & -8.57 & 1.59 \\
\hline 2 & SPA, FI, GR, LU & -14.52 & 2.48 \\
\hline \multicolumn{4}{|c|}{ Price clusters } \\
\hline 1 & GER, AU, BE, IT, FR & -5.89 & 0.14 \\
\hline 2 & FI & 0 & 0 \\
\hline 3 & NTH, IR & -3.79 & 0.0003 \\
\hline 4 & SPA, LU, GR, PO & -9.22 & 1.06 \\
\hline \multicolumn{4}{|c|}{ Period 2} \\
\hline \multicolumn{4}{|c|}{ GDP clusters } \\
\hline 1 & GER, AU, BE, FR, FI & 0.33 & 0.34 \\
\hline 2 & SPA, LU, NTH, IT, PO & -1.99 & 0.92 \\
\hline 3 & GR, IR & -4.84 & 0.004 \\
\hline \multicolumn{4}{|c|}{ Price clusters } \\
\hline 1 & GER, FI, AU, BE, NTH, IR, LU, FR, IT, PO & 0.51 & 0.37 \\
\hline 2 & SPA, GR & 1.8 & 0.33 \\
\hline \multicolumn{4}{|c|}{ Period 3} \\
\hline \multicolumn{4}{|c|}{ GDP clusters } \\
\hline 1 & GER, FI, AU, BE, NTH, SPA, LU, FR, IT, PO, GR & 2.74 & 1.19 \\
\hline 2 & IR & 9.64 & 0 \\
\hline \multicolumn{4}{|c|}{ Price clusters } \\
\hline 1 & GER, PO, AU, BE, FI, FR, GR & 1.43 & 0.81 \\
\hline 2 & SPA, NTH, IT, IR, LU & -0.07 & 0.09 \\
\hline
\end{tabular}

Source: authors' calculations based on data collected in Appendix A.

policy do exist) has not produced clusters in the remaining countries, but has given rise to more homogeneous effects in the Eurozone, reactivating economic activity in all the countries studied. It should, however, be highlighted that Ireland's GDP emerged as considerably more reactive than that of the other countries. Turning to price responses, the ANOVA test confirms the existence of two clusters that barely reacted in quantitative terms to the quantitative easing policy, although the degree of responsiveness is lower in the case of cluster 2 (Spain, Netherlands, Italy, Ireland, and Luxembourg), being this last cluster more compact than cluster 1. In the case of scenario (2) Germany, France and Greece are included in cluster 2, which continues to be less responsive and more compact than cluster 1 . 
In order to check the robustness of the previous conclusions vis-à-vis the clustering method applied, the same clustering analysis was performed for the Complete Linkage method (results available upon request from the authors). Results do not change with regard to the clusters identified since only minor and very few differences are pinpointed between both methods.

\section{Analysis of the factors driving similarities and divergences across geographical space}

\subsection{Methodology}

In order to identify which factors generate similarities and divergences in the effects of monetary policy across euro area countries and thereby shape monetary clusters, we analyse a set of economic variables related to monetary transmission with the aim of determining which of them display within-cluster commonality while differing across clusters for each period examined. In other words, we try to pinpoint whether there are variables that can actually profile the clusters identified. To do this, we perform ANOVA analysis whenever the assumptions of series normality and variance homogeneity required to correctly perform this type of analysis are fulfilled. When this is not the case, we use the non-parametric test of Kruskal-Wallis. We also perform Tukey post-hoc tests (alternatively, Dunn's test whenever it is necessary to apply Kruskal-Wallis) in order to identify, when analysing more than two clusters, amongst which clusters variables differ. The variables used can be found in previous studies applied at the regional or cross-country level such as Carlino and DeFina (1998, 1999), Owyang and Wall (2009), Ridhwan et al. (2014), Georgiadis (2015), Vespignani (2015), Boeckx et al. (2017), Burriel and Galesi (2018) and Elbourne, Ji and Duijndam (2018) and are representative of: (1) the sectorial structure of the economy, since there are economic sectors that are more sensitive to varying monetary conditions; (2) the health of the banking system, since a healthy banking system helps the monetary transmission mechanism to function; (3) each country's level of economic development, which operates in the same direction; (4) the country's degree of economic openness, since it is linked to economy sensitivity to the exchange rate channel, and (5) potential vulnerabilities relating to international financial markets, which might short-circuit monetary transmission channels. For all of these, we use the mean values during each of the periods considered. In addition, we include two variables representing GDP and price volatility for the period 1995-2017. By employing such variables, we seek to determine whether the general long-run propensity towards economic instability in the economies of the countries analysed might also be shaping monetary spatiality. Appendix A details the variables used and their sources.

\subsection{Results}

With regard to GDP clusters, in the first period the ANOVA test does not pinpoint any significant differences between the variables for the two clusters identified. This means that the similarities identified across the geographical space are not driven by factors that are common to the countries comprising each cluster, that is, the clusters are not shaped by economic features exhibiting within-cluster similarity and inter-cluster dissimilarities.

On the contrary, the economic singularities that are specific to each of the countries which make up the most reactive cluster seem to be the factors which might explain this more reactive pattern. This is the case of Luxembourg, a country for which the great weight of the banking and financial sector, together with the importance of loans granted by non-residents, might explain (at least partially) its greater reactivity to monetary policy (the Grubbs test confirms that such 
variables are outliers with regard to their respective series). Something similar occurs in the case of Spain since, even if the Grubbs test does not qualify the Spanish construction sector as an outlier, it is noticeably further from the rest. Coupled with the fact that Spain has one of the lowest financing costs in real terms of the whole euro area might explain (once again, at least partially) its greater reactivity.

As regards price clusters, post-hoc tests point to significant differences in terms of price volatility between the most reactive cluster (Spain, Luxembourg, Greece, and Portugal) and the remaining clusters. The industry share does also seem to differ between clusters 2 and 4 . However, none of the other drivers analysed differ between clusters 1,2 and 3. As a result, we are unable to provide an explanation beyond the role of price propensity to greater long-term volatility in the countries in cluster 4.

In period 2, there are, however, factors exhibiting within-cluster commonality. Such factors constitute an economic profile that could well explain the similarities and divergences identified. Specifically, as seen in Table 4, the drivers that differentiate cluster 3 (Greece and Ireland) in terms of GDP from clusters 1 and 2 correspond to a worse banking system (according to the indicators of non-performing loans and return on assets). Furthermore, the stress in the sovereign bond market and the output gap also drive the differences between clusters 1 and 3. Sovereign bond market stress also differentiates cluster 1 from cluster 2. However, one point should be highlighted with regard to the role of sovereign bond market stress in the conformation of cluster 2. Namely, it is important to point out that Luxembourg and the Netherlands are also included in cluster 2 even though their sovereign bond markets experienced a considerably lower degree of stress than the rest of the countries that make up the cluster. The explanation to their inclusion in cluster 2 can be found in the dependence on external credit and private over-indebtedness, since as Duchi and Elbourne (2016) suggest in the case of the Netherlands, those features made countries prone to spillover effects from the sovereign debt crises.

As regards price clusters, in addition to stress in the sovereign debt market and the output gap, long-term price volatility also drives differences between clusters (Tables 5 and 6).

For period 3, none of the variables analysed is a driver of the clusters identified, except for industry share, which differentiates the Ireland cluster/outlier in the case of GDP. It can therefore be concluded that price clusters are not shaped by the economic conditions which the variables analysed represent (the same holds for scenario (2)).

\section{Recapitulation and consequences for European monetary policy}

As pointed out in the introduction, the main goals of this study were to determine not only whether the monetary policy implemented by the ECB triggers differential economic outcomes across Eurozone countries but also the following issues: (1) the identification and quantification of the patterns of spatial distribution of the effects exerted by monetary policy on economic activity, that is, whether there are similarities and divergences in the obtained effects across countries which result in the conformation of groups of countries according to the similarities identified; (2) the factors which seem to shape the spatial distribution of monetary policy effects on economic activity and which explain similarities and divergences in such effects across countries and, finally, (3) whether the results to emerge might justify the discrepancies expressed by some countries, mainly Germany, in relation to ECB monetary policy or, in other words, whether the spatiality of monetary policy justifies different and even contrasting interests regarding the implementation of monetary policy within the Eurozone. 
Table 4

ANOVA analysis results for GDP and price clusters.

\begin{tabular}{|c|c|c|c|c|c|c|}
\hline \multirow[t]{2}{*}{ Explanatory factor } & \multicolumn{2}{|l|}{ Period 1} & \multicolumn{2}{|l|}{ Period 2} & \multirow{2}{*}{$\begin{array}{l}\text { Period } 3 \\
\text { GDP clusters }\end{array}$} & \multirow[b]{2}{*}{ Price clusters } \\
\hline & GDP clusters & Price clusters & GDP clusters & Price clusters & & \\
\hline Industry share & $\mathrm{F}=1.12(0.3)$ & $\begin{array}{l}\mathrm{F}=3.53 \text { *** } \\
(0.06) \\
4 v s 2^{* * * *} \\
(0.08)\end{array}$ & $\mathrm{F}=1.12(0.36)$ & $\mathrm{F}=0.78(0.39)$ & $\mathrm{F}=14.36^{*}(0.003)$ & $\mathrm{F}=0.01(0.94)$ \\
\hline Construction share & $\mathrm{F}=2.45(0.14)$ & $\mathrm{F}=1.57(0.27)$ & $\begin{array}{l}F=4^{\text {kw/no sig }} \\
(0.03)\end{array}$ & $\mathrm{F}=0.27(0.61)$ & $\mathrm{F}=3.6(0.08)$ & $\mathrm{F}=0.19(0.67)$ \\
\hline Services share & $\mathrm{F}=0.04(0.8)$ & $\mathrm{F}=1.2(0.35)$ & $\begin{array}{l}F=0.9 \\
(0.4)\end{array}$ & $\mathrm{F}=0.15(0.7)$ & $\mathrm{F}=8.16(0.01)$ & $\mathrm{F}=0.01(0.93)$ \\
\hline $\begin{array}{l}\text { Banking sector } \\
\text { size } \\
(\% \text { of GDP) }\end{array}$ & $\mathrm{F}=1.4^{\mathrm{kw}}(0.26)$ & $\mathrm{F}=0.46^{\mathrm{kw}}(0.71)$ & $\mathrm{F}=0.52^{\mathrm{kw}}(0.6)$ & $\mathrm{F}=0.36^{\mathrm{kw}}(0.56)$ & $\mathrm{F}=0^{\mathrm{kw}}(0.95)$ & $\mathrm{F}=1.84^{\mathrm{kw}}(0.2)$ \\
\hline $\begin{array}{l}\text { Bank capital to } \\
\text { assets ratio (\%) }\end{array}$ & - & - & $\mathrm{F}=2.05(0.18)$ & $\mathrm{F}=1.8(0.2)$ & $\begin{array}{l}\mathrm{F}=20^{\mathrm{kw} / \mathrm{no} \mathrm{sig}} \\
(0.001)\end{array}$ & $\mathrm{F}=0.36(0.56)$ \\
\hline $\begin{array}{l}\text { Non performing } \\
\text { loans }(\%)\end{array}$ & - & - & $\begin{array}{l}\mathrm{F}=14.33^{* \mathrm{kw}} \\
(0.001) \\
3 \text { vs } 1^{*}(0.01) \\
3 \text { vs } 2^{* *}(0.04) \\
\mathrm{F}=20.5^{* \mathrm{kw}}\end{array}$ & $\mathrm{F}=2.41(0.15)$ & $\mathrm{F}=0.15(0.7)$ & $\mathrm{F}=0.09(0.77)$ \\
\hline $\begin{array}{l}\text { Return on assets } \\
(\%)\end{array}$ & - & - & $\begin{array}{l}(0.000) \\
3 \text { vs } 1^{*}(0.01) \\
3 \text { vs } 2^{* *}(0.03)\end{array}$ & $\mathrm{F}=2.65^{\mathrm{kw}}(0.13)$ & $\mathrm{F}=1.53(0.24)$ & $\mathrm{F}=1.35(0.27)$ \\
\hline $\begin{array}{l}\text { GDP per capita } \\
\text { (euro per capita) }\end{array}$ & $\mathrm{F}=0.4^{\mathrm{kw}}(0.5)$ & $\mathrm{F}=0.15^{\mathrm{kw}}(0.9)$ & $\mathrm{F}=0.16^{\mathrm{kw}}(0.8)$ & $\mathrm{F}=1.78(0.21)$ & $\mathrm{F}=0.99(0.34)$ & $\mathrm{F}=2.21(0.17)$ \\
\hline Trade openness & $\mathrm{F}=0.33^{\mathrm{kw}}(0.5)$ & $\mathrm{F}=0.35^{\mathrm{kw}}(0.8)$ & $\mathrm{F}=0.23(0.8)$ & $\mathrm{F}=1.19^{\mathrm{kw}}(0.3)$ & $\mathrm{F}=0.75(0.4)$ & $\mathrm{F}=2.6(0.14)$ \\
\hline
\end{tabular}


Table 4 (Continued)

\begin{tabular}{|c|c|c|c|c|c|c|}
\hline \multirow[t]{2}{*}{ Explanatory factor } & \multicolumn{2}{|l|}{ Period 1} & \multicolumn{2}{|l|}{ Period 2} & \multirow{2}{*}{$\begin{array}{l}\text { Period } 3 \\
\text { GDP clusters }\end{array}$} & \multirow[b]{2}{*}{ Price clusters } \\
\hline & GDP clusters & Price clusters & GDP clusters & Price clusters & & \\
\hline $\begin{array}{l}\text { Energy } \\
\text { Dependence }(\%)\end{array}$ & $\mathrm{F}=2.8^{\mathrm{kW}}(0.12)$ & $\begin{array}{l}F=1.72^{\mathrm{kw}} \\
(0.23)\end{array}$ & $\begin{array}{l}F=0.26 \\
(0.77)\end{array}$ & $\begin{array}{l}F=0.58 \\
(0.46)\end{array}$ & $\begin{array}{l}F=0.63 \\
(0.44)\end{array}$ & $\begin{array}{l}F=0.05 \\
(0.82)\end{array}$ \\
\hline $\begin{array}{l}\text { Loans granted by } \\
\text { non-residents ( } \% \\
\text { of GDP) }\end{array}$ & $\mathrm{F}=1.87^{\mathrm{kW}}(0.2)$ & $\mathrm{F}=0.53^{\mathrm{kw}}(0.67)$ & $\mathrm{F}=0.65(0.54)$ & $\mathrm{F}=0.2(0.66)$ & $\mathrm{F}=0^{\mathrm{kw}}(0.95)$ & $\mathrm{F}=1.76(0.21)$ \\
\hline $\begin{array}{l}\text { Current plus } \\
\text { capital account } \\
\text { balance } \\
\text { (\% of GDP) }\end{array}$ & $\mathrm{F}=0.03(0.8)$ & $\mathrm{F}=0.89^{\mathrm{kw}}(0.48)$ & $\mathrm{F}=1.76(0.22)$ & $\mathrm{F}=3.53(0.089)$ & $\mathrm{F}=1.02^{\mathrm{kw}}(0.33)$ & $\mathrm{F}=0.82(0.39)$ \\
\hline $\begin{array}{l}\text { Government debt } \\
\text { (\% of GDP) }\end{array}$ & $\mathrm{F}=0.96(0.35)$ & $\mathrm{F}=1.28(0.34)$ & $\mathrm{F}=1.63(0.24)$ & $\mathrm{F}=1.66(0.22)$ & $\mathrm{F}=0.23(0.64)$ & $\mathrm{F}=1.18(0.3)$ \\
\hline Output gap (\%) & $\mathrm{F}=2.8(0.12)$ & $\mathrm{F}=1.08(0.41)$ & $\begin{array}{l}\mathrm{F}=5.8^{* *}(0.02) \\
3 \text { vs } 1^{*}(0.02) \\
\mathrm{F}=6.79^{* * \mathrm{kw}}\end{array}$ & $\begin{array}{l}F=19.46^{*} \\
(0.0013)\end{array}$ & $\mathrm{F}=0.99(0.34)$ & $\mathrm{F}=0.17(0.69)$ \\
\hline Sovereign CISS & $\mathrm{F}=1.68^{\mathrm{kw}}(0.22)$ & $\mathrm{F}=0.24^{\mathrm{kw}}(0.86)$ & $\begin{array}{l}(0.01) \\
3 \text { vs } 1^{*}(0.01)^{*}\end{array}$ & $\mathrm{~F}=7.25^{* *}(0.02)$ & $\mathrm{F}=0.54^{\mathrm{kw}}(0.48)$ & $\mathrm{F}=0.8^{\mathrm{kw}}(0.39)$ \\
\hline GDP volatility & $\mathrm{F}=0.73(0.41)$ & $\overline{\mathrm{F}}=6.48^{\mathrm{kW} *}(0.01)$ & $\mathrm{F}=0.7(0.52)$ & - & $\mathrm{F}=0.12(0.73)$ & - \\
\hline HICP volatility & - & $\begin{array}{l}4 \text { vs } 1(0.005)^{*} \\
4 \text { vs } 2(0.03)^{* *} \\
4 \text { vs } 3(0.05)^{* *}\end{array}$ & - & $\mathrm{F}=9.31 *(0.01)$ & - & $\mathrm{F}=1.08(0.32)$ \\
\hline
\end{tabular}

Source: authors' calculations based on data collected in Appendix A.

Note: the table includes the F statistics of the ANOVA tests and their corresponding P-values. In the case the Kruskal-Wallis test has been applied, results display the superscript "kw" when the same conclusions are drawn from applying both an ANOVA and a Kruskal-Wallis test (that is, results are robust to both types of tests), whereas the superscript "kw/no sig" indicates the opposite. The cursive lines report the statistically significant pairwise comparisons reported by post-hoc tests (in the case more than two clusters exist) and their corresponding $\mathrm{p}$-values in parentheses.

* Denote respectively significance at the $1 \%$.

** Denote respectively significance at the $5 \%$.

**** Denote respectively significance at the $10 \%$. 
Table 5

Profile of the identified drivers by GDP clusters. Period 2.

\begin{tabular}{|c|c|c|c|c|c|c|c|c|c|}
\hline \multirow[t]{2}{*}{ GDPclusters } & \multirow[t]{2}{*}{ Clusters means } & \multicolumn{2}{|c|}{ Non performing loans } & \multicolumn{2}{|c|}{ Return on assets } & \multicolumn{2}{|c|}{ Output gap } & \multicolumn{2}{|c|}{ Sovereign CISS } \\
\hline & & Mean & Std. Dev. & Mean & Std. Dev. & Mean & Std. Dev. & Mean & Std. Dev. \\
\hline 1 & 0.33 & 2.8 & 0.98 & 0.28 & 0.16 & -1.13 & 0.41 & 0.21 & 0.03 \\
\hline 2 & -1.9 & 5.8 & 4.5 & 0.10 & 0.31 & -3.33 & 2.17 & $0.38 / 0.5^{\mathrm{a}}$ & $0.15 / 0.05^{\mathrm{a}}$ \\
\hline 3 & -4.84 & 16.8 & 1.2 & -1.11 & 0.35 & -5.18 & 1.03 & 0.56 & 0.13 \\
\hline
\end{tabular}

Source: authors' calculations based on data collected in Appendix A.

a Mean and standard deviation of cluster 2 excluding Luxembourg and the Netherlands.

Table 6

Profile of the identified drivers by price clusters. Period 2.

\begin{tabular}{|c|c|c|c|c|c|c|c|}
\hline \multirow[t]{2}{*}{ Prices clusters } & \multirow[t]{2}{*}{ Clusters means } & \multicolumn{2}{|c|}{ Output gap } & \multicolumn{2}{|c|}{ Sovereign CISS } & \multicolumn{2}{|c|}{ HICP volatility } \\
\hline & & Mean & Std. Dev. & Mean & Std. Dev. & Mean & Std. Dev. \\
\hline 1 & 0.51 & -2 & 1.31 & 0.29 & 0.13 & 10.82 & 1.17 \\
\hline 2 & 1.8 & -6.33 & 0.59 & 0.58 & 0.12 & 13.5 & 0.7 \\
\hline
\end{tabular}

Source: authors' calculations based on data collected in Appendix A.

Results suggest that the Eurozone does indeed evidence different spatial GDP and price outcomes stemming from monetary policy within the cross-country dimension. This confirms previous studies such as those by Boeckx et al. (2017) and Burriel and Galesi (2018). The degree of heterogeneity is greater in the period corresponding to conventional monetary policy (period 1) than in periods 2 and 3, which correspond, respectively, to the periods of policy transition and quantitative easing, since results display a more compact pattern in these latter two periods.

Cluster analysis leads to the conclusion that what we term "monetary clusters" do indeed exist, such that the euro area is segmented into blocks or clusters according to the similarities identified across countries in the effects exerted by monetary policy on economic activity. While the results indicate that the number of clusters and their geographical composition varies across the periods and policies analysed, the varying spatial distribution of these effects has not been found to follow a clustered spatial pattern in any of the periods considered. The spatial dynamics arising from implementing ECB monetary policy therefore seem to be more complex than the traditional core-periphery approach would appear to suggest and seem to respond to factors related not only to the structural features of the economies. With regard to period 1 , that is, the period of conventional monetary policy, the impacts stemming from a monetary contractive shock are noticeably greater in terms of GDP for a more reactive cluster of countries comprising Spain, Greece, Luxembourg, and Finland, although no common drivers for the countries in this more reactive group are identified. We therefore consider that this more reactive pattern results from individual country-specific singularities representative of structural economic features, which give rise to a more reactive cluster. As for prices, the most important conclusion again involves identifying a more reactive cluster composed of Spain, Greece, Luxembourg, and Portugal for which the propensity to long-run price volatility is pinpointed as the explanatory factor for its higher reactivity.

With regard to the quantitative easing period, the clusters identified on the basis of GDP impacts are diluted since ECB monetary policy produces more uniform spatial effects, with the sole exception of Ireland, which behaves as an outlier due to its economic-structural singularities, 
which are reflected in industry share. Therefore, it is again an economic structural singularity which drives the hyper-reactive outcome of Ireland. As regards prices, a two-block segmentation emerges, although it should be noted that price reaction was very small in both clusters.

Period 2, which spans the international financial crisis and the sovereign debt crisis, is both the most complex and the most interesting. Results suggest that ECB monetary policy segmented countries across blocks that not only exhibit quantitative differences in their responses but also divergences of a qualitative nature, which is particularly worrying in a context in which the real economy is striving for reactivation. With regard to GDP, the monetary policy which we describe as temporary quantitative easing proved slightly effective for reactivating the economy of cluster 1, comprising Germany, Austria, Belgium, France, and Finland, although it proved ineffective for the two other blocks, although with differences between them. The drivers shaping these clusters are those representing key aspects of both crises, such as non-performing loans and return on assets, together with the variable associated to stress in the sovereign bonds market, which proxies for the difficulties of certain sovereign governments in accessing financing in capital markets. In other words, spatial differences were conditioned in that period by doubts surrounding the banking system and expectations regarding countries' fiscal viability, normally linked to the viability of their banking system. In normal conditions, such as period 1, these variables do not, however, seem to shape the clusters. Drivers of segmentation by blocks in terms of price responses basically follow the same pattern, since the variables identified as relevant are once again stress in the sovereign debt market, the output gap, and price propensity to volatility.

Thus far, we have provided answers to questions 1 and 2 set out at the beginning of this section. We can now answer question 3 which, as will be recalled, concerned justifying Germanyś critical stance. Based on our results, ECB monetary policy has never proven negative for Germany. Taking these results, Germany is characterised by having a low degree of GDP responsiveness to conventional monetary policy, and is thus less affected by such a policy. In period 2 of crisis and non-conventional pre-quantitative easing policy, Germany belongs to the group displaying a more positive response, whereas in period 3, or the period of quantitative easing in strict terms, its response is central given the compactness of the results. All in all, it does not seem that the stance against ECB monetary policy in Germany can be justified on the basis of the effects of such a policy, and much less so in period 2. It thus seems likely that in the background the motivation underlying such an opposition is more linked to what Brunnermeier et al. (2016) refer to as "the battle of ideas".

In terms of economic policy, since the analysis carried out reveals both the existence of differentiated spatial effects stemming from ECB monetary policy and the conformation of monetary clusters, that is, it reveals the existence of divergences and similarites in the effects across geographical space, monetary policy must take into account this different territorial impact. Since spatial differences and clusters in terms of prices are linked to the long-run volatility of prices in each country and to the productive structure, it is likely that the fact that contractive antiinflationary conventional monetary policies have a greater impact on more inflationist countries does not pose a problem, provided of course there is no asymmetrical crisis or extreme cyclical asynchrony. In these latter two cases, the problem becomes more complex and would require further instruments that should come from fiscal policy, given the limitation imposed by a single currency system.

Period 2, however, teaches us different lessons. The most important of these is that if there are a set of countries with a banking system that is in crisis and/or which are highly unstable in their sovereign debt market, the priority is first to deal with and guarantee bank solvency and to stabilize sovereign debt markets so that expansionary monetary policy can bring benefit 
to all countries and prove effective. This conclusion works in favour of the ECB assuming the functions of banking supervision and banking crisis resolution and, of course, also lends support to the well-known OMT, a measure which should have been promoted much earlier. However, as regards the latter, it is also true that the results for period 3, and their comparison to period 2, show us that the OMT, which caused so many internal problems in the ECB and in the euro area, need not have been applied if quantitative easing had been implemented much earlier, perhaps applying a similar timing to the FED's own quantitative expansion. Had this actually been the case, the sovereign debt crisis would probably have never occurred or would have proven almost irrelevant.

Finally, the knowledge to be gleaned from period 3 in terms of monetary policy and economic policy is that quantitative easing does not entail acute differential effects. Spatial differences therefore again lose relevance, although in this case not because monetary policy has a greater impact on countries that should indeed be more affected but rather because differences are diluted and become noticeably lower, and indeed to a certain extent, irrelevant.

Summing up, the spatial analysis carried out reveals that monetary clusters (that is, the similarities and divergences in the economic outcomes of monetary policy across countries) can either operate in favour of monetary policy, as is the case in period 1 of conventional monetary policy; be barely relevant, as in period 3 of quantitative easing, or be the manifestation of priority problems that the ECB must resolve beforehand if it wishes to apply an effective monetary policy. ECB effectiveness is key to the euro area and the viability of its currency.

\section{Appendix A. Data sources and construction of variables}

ECB Main refinancing operations rate: Euro area (changing composition) Interest rate on ECB Main refinancing operations (fixed rate and variable rate tenders (minimun bid rate)) - Level - Euro, percent per annum (unit). Monthly data: end-of-month values. Source: European Central Bank (ECB Statistical Data Warehouse).

ECB balance sheet: Euro area (changing composition) Total assets/liabilities. Million of Euro. Monthly frequency obtained by the average of observations through the period of reference (month). Source: European Central Bank. ECB Statistical Data Warehouse.

Gross Domestic Product: Gross domestic product at market prices, Chain linked volumes (2010), million euro, Seasonally and calendar adjusted data, Euro area changing composition. Monthly frequency derived by interpolating the original quarterly data. Source: Eurostat.

HICP: Harmonised consumer prices - all items. Index $2010=100$, monthly frequency. Seasonal adjustment to the data using the Census X12 procedure. Source: OCDE.

CISS: Composite Indicator of Systemic Stress (CISS) Index, Euro area (changing composition), monthly frequency, unit-free. Monthly frequency obtained by the average of observations through the period of reference (month). Source: ECB Statistical data Warehouse.

Industrial production Index: Volume index of production, Seasonally and calendar adjusted data, Index, $2010=100$. Source: Eurostat.

- Mining and quarrying; manufacturing; electricity, gas, steam and air conditioning supply and construction: all the countries with the exception of Ireland and Greece. Euro Area (19 countries).

- Mining and quarrying; manufacturing; electricity, gas, steam and air conditioning supply: Greece and Ireland. 
Industry share (IS): Industry, including energy, \% of value added. Source: OECD National Accounts Statistics: National Accounts at a Glance.

Construction share (CS): Construction, \% of value added. Source: OECD National Accounts Statistics: National Accounts at a Glance.

Services share (SS): Services, \% of value added. Source: OECD National Accounts Statistics: National Accounts at a Glance.

Banking sector (BS): Assets of MFIs (excluding ESCB) to GDP. Source: author's calculations from data from ECB Statistical data Warehouse and Eurostat.

- Assets of MFIs: Outstanding amounts at the end of the period (stocks), MFIs excluding ESCB reporting sector - Total Assets/Liabilities, Total maturity, All currencies combined - World not allocated (geographically) counterpart, Unspecified counterpart sector sector, denominated in Euro, data Neither seasonally nor working day adjusted. Source: European Central Bank, ECB Statistical data Warehouse.

Trade openness (\% of GDP) (TB): Trade is the sum of exports and imports of goods and services measured as a share of gross domestic product. Source: World Bank national accounts data, and OECD National Accounts data files.

Output gap (OG): deviations of actual GDP from potential GDP as \% of potential GDP. Source: OECD Statistics.

Loans granted by non-residents (\% of GDP). Source: author's calculations from data from European Central Bank, ECB Statistical data Warehouse and Eurostat.

- Loans granted by non-residents: Closing balance sheet/Positions/Stocks - Loans - Longterm original maturity (over 1 year or no stated maturity). Source: European Central Bank, ECB Statistical data Warehouse.

Non performing loans: this FSI is calculated by using the value of NPLs as the numerator and the total value of the loan portfolio (including NPLs, and before the deduction of specific loan- loss provisions) as the denominator. Source: IMF Financial Soundness indicators.

Return on assets: this FSI is calculated by dividing net income before extraordinary items and taxes (as recommended in the FSI Guide) by the average value of total assets (financial and nonfinancial) over the same period. Source: IMF Financial Soundness indicators.

Bank capital to assets ratio (\%) (BC): Bank capital to assets is the ratio of bank capital and reserves to total assets. Source: World bank development indicators.

SovCISS: composite indicator of sovereign bond market stress. Monthly frequency obtained by the average of observations through the period of reference (month). Source: European Central Bank, ECB Statistical data Warehouse. For the case of Luxembourg, since the SovCISS is not available, we use as a proxy for the stress level in the market of sovereign bonds the Country-Level Index of Financial Stress (CLIFS) calculated by the ECB and available at ECB Statistical data Warehouse.

Current plus capital account $($ balance $=$ Net lending $(+) /$ net borrowing $(-))(\mathrm{CA})$ : Current plus capital account $($ balance $=$ Net lending $(+) /$ net borrowing $(-))$ as percentage of gross domestic product (GDP). Partner: rest of the world. Balance. Source: Eurostat.

Government debt (GD): General government, consolidated gross debt as percentage of gross domestic product. Source: Eurostat. 
GDP per capita (GDPC): Current prices, euro per capita. Source: Eurostat. Energy Dependence (total petroleum products, ED): Energy dependency shows the extent to which an economy relies upon imports in order to meet its energy needs. The indicator is calculated as net imports divided by the sum of gross inland energy consumption plus bunkers. Source: Eurostat.

\section{References}

Boeckx, J., Dossche, M., \& Peersman, G. (2017). Effectiveness and transmission of the ECB's balance sheet policies. International Journal of Central Banking, 13(1), 297-333.

Borrallo Egea, F., \& Hierro, L. A. (2019). Transmission of monetary policy in the US and EU in times of expansion and crisis. Journal of Policy Modeling, 41, 763-783.

Brunnermeier, M. K., James, H., \& Landau, J.-P. (2016). The euro and the battle of ideas. Princeton, NJ, USA: Princeton University Press.

Burriel, P., \& Galesi, A. (2018). Uncovering the heterogeneous effects of ECB unconventional monetary policies across euro area countries. European Economic Review, 101, 210-229.

Carlino, G., \& DeFina, R. (1998). The differential regional effects of monetary policy. Review of Economics and Statistics, $80(4), 572-587$.

Carlino, G., \& DeFina, R. (1999). The differential regional effects of monetary policy: Evidence from the U.S. States. Journal of Regional Science, 39(2), 339-357.

Cavallo, A., \& Ribba, A. (2015). Common macroeconomic shocks and business cycle fluctuations in euro area countries. International Review of Economics and Finance, 38, 377-392.

Cavallo, A., \& Ribba, A. (2018). Measuring the effects of oil price and Euro-area shocks on CEECs business cycles. Journal of Policy Modeling, 40, 74-96.

Chow, G. C., \& Lin, A. L. (1971). Best linear unbiased interpolation, distribution, and extrapolation of time series by related series. The Review of Economics and Statistics, 53(4), 372-375.

Dominguez-Torres, H., \& Hierro, L. A. (2019). The regional effects of monetary policy: A survey of the empirical literature. Journal of Economic Surveys, 33(2), 604-638.

Duchi, F., \& Elbourne, A. (2016). Credit supply shocks in the Netherlands. CBP Discussion Paper, 320.

Duda, R. O., Hart, P. E., \& Stork, D. G. (2001). Pattern classification (2nd ed.). New York: Wiley.

Elbourne, A., Ji, K., \& Duijndam, S. (2018). The effects of unconventional monetary policy in the euro area. CPB Discussion Paper 371.

Fisher, R. A. (1925). Statistical methods for research workers. Oliver \& Boyd: Edinburgh.

Gambacorta, L., Hofmann, B., \& Peersman, G. (2014). The effectiveness of unconventional monetary policy at the zero lower bound: A cross-country analysis. Journal of Money, Credit and Banking, 46(4), 615-642.

Georgiadis, G. (2015). Examinig asymmetries in the transmission of monetary policy in the euro area: Evidence from a mixed cross-section global VAR model. European Economic Review, 75, 195-215.

De Grauwe, P. (2011). The European Central Bank as a lender of last resort 18/8/2011. Retrieved from:. VOX. https://voxeu.org/article/european-central-bank-lender-last-resort

Guo, X., \& Tajul, A. M. (2017). Regional effects of monetary policy in China: Evidence from China's provinces. Bulletin of Economic Research, 69(2), 178-208.

Hewings, G. J. D. (2014). Spatially blind trade and fiscal impact policies and their impact on regional economies. The Quarterly Review of Economics and Finance, 54, 590-602.

Holló, D., Kremer, M., \& Lo Duca, M. (2012) CISS - a Composite Indicator of Systemic Stress in the financial system. ECB Working Paper No. 1426, March 2012.

Kremer, M. (2016). Macroeconomic effects of financial stress and the role of monetary policy: A VAR analysis for the euro area. International Economics and Economic Policy, 13, 105-138.

Krugman, P. (2012). End this depression now!. New York: W.W. Norton \& Company.

Mann, G. (2010). Hobbes' redoubt? Toward a geography of monetary policy. Progress in Human Geograph, 1-25.

Mooi, E., \& Sarstedt, M. (2014). A concise guide to market research. The process, data, and methods using IBM SPSS statistics. Springer Texts in Business and Economics. Springer.

Mooi, E., Sarstedt, M., \& Mooi-Reci, I. (2018). Market research: The process, data, and methods using stata. Springer Texts in Business and Economics. Springer. 
Owyang, M. T., \& Wall, H. J. (2009). Regional VARs and the channels of monetary policy. Applied Economics Letters, 16(12), 1191-1194.

Ridhwan, M. M., de Groot, H. L. F., Rietveld, P., \& Nijkamp, P. (2014). The regional impact of monetary policy in Indonesia. Growth and Change, 45(2), 240-262.

Rocha, R. M., Silva, M. E. A., \& Gomes, S. M. F. P. O. (2011). Por que os estados brasileiros têm reações assimétricas a choques na política monetária? Revista Brasileira de Economia, 65(4), 413-441.

Rousseeuw, P. J. (1987). Silhouettes: A graphical aid to the interpretation and validation of cluster analysis. Journal of Computational and Applied Mathematics, 20, 53-65.

Sáinz de Vicuña Barroso, A. (2016). La política monetaria del BCE ante el Tribunal Constitucional Federal Alemán: la Sentencia de 21 de junio de 2016 en el caso «OMT». Revista de Derecho Comunitario Europeo, 55, 1067-1099.

Stiglitz, J. E. (2016). The euro: How a common currency threatens the future of Europe. New York: W.W. Norton \& Company.

Thorndike, R. L. (1953). Who belong in the family? Psychometrika, 18(4), 267-276.

Vespignani, J. L. (2015). On the differential impact of monetary policy across states/territories and its determinants in Australia: Evidence and new methodology from a small open economy. Journal of International Financial Markets, Institutions \& Money, 34, 1-13.

Ward, J. H., Jr. (1963). Hierarchical grouping to optimize an objective function. Journal of the American Statistical Association, 58, 236-244. 